
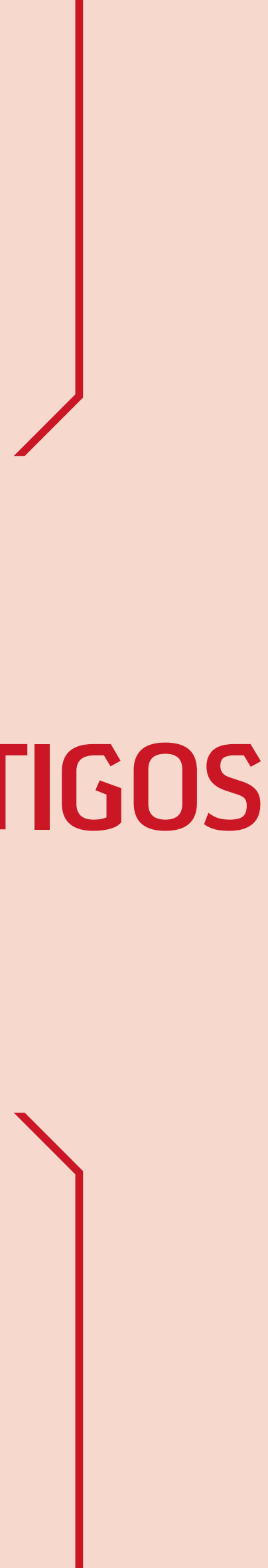


\section{ESSES MARES SÃO NAVEGÁVEIS? A LITERATURA COMO PARTICIPANTE E NÃO APENAS COADJUVANTE NO ENSINO DE HISTÓRIA}

\section{MARCELO ADRIANO BUGNI*}

Universidade Presbiteriana Mackenzie (UPM), Programa de Pós-Graduação em Letras (PPGL), São Paulo, SP, Brasil.

Recebido em: 21 ago. 2020. Aprovado em: 8 set. 2020.

Como citar este artigo: BUGNI, M. A. Esses mares são navegáveis? A literatura como participante e não apenas coadjuvante no ensino de História. Cadernos de Pós-Graduação em Letras, v. 21, n. 1, p. 153-169, jan./abr. 2021. doi: 10.5935/cadernosletras.v21n1p153-169

\section{Resumo}

O presente artigo procura discutir a utilização de textos literários para o apoio e ensino da disciplina de História desejando ultrapassar a questão ou utilização da literatura apenas como fornecedora de exemplos. Compreendemos como uma limitação imposta ao texto literário esse uso e propomos a exploração da literatura como possibilidades para o enriquecimento do ensino de História, como também o estímulo dos alunos à leitura de textos literários além da disciplina de Língua Portuguesa e Literatura.

* E-mail: marcelobugni@hotmail.com

(DD https://orcid.org/0000-0002-4484-6548

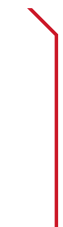




\section{Palavras-chave}

Literatura. História. Ensino.

\section{INTRODUÇÃO}

Em uma peça de teatro, em um filme ou mesmo em um texto literário, encontramos personagens coadjuvantes, pois as ocupações que lhes são atribuídas são secundárias, fazem parte da peça, mas não são personagens principais, bem como são substituídos com maior facilidade. Assim, também compreendemos que a utilização da literatura na disciplina de História ocupa um lugar de coadjuvante, é secundária, ou mesmo nem chega a ocupar um lugar de coadjuvante, sendo utilizada como "parte do cenário", ou ainda está completamente ausente.

Compreendemos que a literatura pode ocupar um lugar de maior destaque dentro da disciplina de História, muito além de oferecer exemplos ou mesmo breves citações ao serem abordados determinados períodos e eventos na História, como citar apenas “por mares nunca dantes navegados” quando o conteúdo das navegações nos séculos XV e XVI é trabalhado com os alunos.

A História procura trabalhar com diversas fontes, e, entre elas, a escrita ocupa um lugar privilegiado, inclusive na divisão entre pré-história e história, como elemento que assinala essa divisão. Portanto, textos escritos em seus mais diferentes suportes são peças importantes para os estudos históricos, são fontes históricas, e a literatura, como textos escritos, também deve ser trabalhada na disciplina em questão.

Comparando com um quadro, o uso de textos da literatura na disciplina de História pode fazer parte da tela e não apenas servir de moldura ou, utilizando novamente o exemplo do teatro, pode fazer parte do elenco e não apenas servir de objeto de decoração no palco.

Pensando em uma maior utilização dos textos literários dentro dos conteúdos de História, ao analisarmos os materiais disponibilizados aos alunos, especificamente os livros didáticos e as apostilas, temos maior dificuldade em encontrar a utilização de textos literários como apoio para o ensino de História, novamente afirmando que encontramos esparsas citações, isso quando as temos, pois, em grande medida, sequer conseguimos encontrar uma citação ou 
referência a um texto literário dentro dos conteúdos expostos nos livros didáticos e nas apostilas de História.

Então, no presente artigo, apresentamos uma proposta de um trabalho conjunto entre a disciplina de História e a utilização de textos literários, não servindo estes últimos apenas como exemplos ou esparsas citações, por vezes, até mesmo descontextualizadas ou, ainda, utilizadas apenas como ilustrações, como um mero "enfeite" dos conteúdos da disciplina de História.

Não é novidade ou mesmo um fato velado que os alunos nos mais diversos segmentos do ensino (o fundamental, o médio e inclusive o ensino superior) pouco leem e, quando leem, o fazem por exigências para a realização de algum trabalho escolar, são leituras obrigatórias literalmente. "O navio negreiro”, de Castro Alves, é tarefa solicitada pela disciplina de Língua Portuguesa e Literatura, mas ocasionalmente trabalhado em conjunto com a disciplina de História, como exemplificação da obrigatoriedade de certas leituras sem o aproveitamento de múltiplas possibilidades de um trabalho interdisciplinar.

Exceções à parte, não é integrante de nossa cultura a valorização pela leitura, e, diante dessa observação, não podemos atribuir apenas aos professores de Língua Portuguesa e/ou Literatura (quando existe essa disciplina específica nas escolas) a tarefa de incentivar e estimular os alunos a adquirir o hábito da leitura, a fruição na leitura. Nossa compartimentalização ${ }^{1}$ dos conteúdos escolares limita muitas possibilidades de um ensino interdisciplinar em que uma disciplina colabora e é beneficiada com essa interdisciplinaridade, na qual existe uma relação de mutualidade.

Podem-se objetar as alegações que inicialmente fizemos com relação às citações de textos literários nos livros didáticos e nas apostilas utilizados na disciplina de História, afirmando que temos muitos exemplos de textos literários nesses materiais, em especial nos exercícios de fixação do conteúdo, em que encontramos várias referências e citações de textos da literatura. Tais referências não significam a leitura e compreensão desses textos, não possibilitam a fruição desses textos.

Comumente, encontramos uma citação de Os lusíadas, Camões, nos conteúdos referentes à expansão colonial marítima, na maioria das vezes apenas

1 Por compartimentalização entendemos a separação entre as disciplinas, como se cada uma tivesse um compartimento a ser ocupado, fechado, limitado, sem a possibilidade da ligação com outras disciplinas. Assim, quando um professor de História trabalha com textos de literatura, é interpelado: "Mas esse conteúdo não é de Língua Portuguesa/Literatura?” e vice-versa, bem como entre outras disciplinas. 
os primeiros versos são citados ou então, o poema "Mar português", de Fernando Pessoa, não sendo ampliada nenhuma outra questão, somente a citação como ilustração do conteúdo exposto.

Quando a literatura é utilizada apenas sob essa ótica de ilustrar ou exemplificar, temos a sujeição do texto literário, de acordo com Sanches Neto (2013, p. 89), a um

[...] processo de utilitarização, sofrendo usos diferentes, mas sempre em uma posição secundária. Campo para estudos gramaticais, estilísticos, históricos, linguísticos, filosóficos, psicanalíticos etc., o texto literário padece de uma falta de autonomia dentro do que se convencionou chamar de Ciências Humanas. Nega-se a ele um poder formador independente, devendo o seu estudo atrelar-se a outras questões, que the dariam o sentido profundo, sem o qual ele não passaria de uma peça de entretenimento.

Assim, na disciplina de História, a obra Os lusiadas serve como simples ilustração aos acontecimentos, ao desbravamento português por mares nunca dantes navegados.

Compreendemos que tal utilização dos textos literários, adotados na disciplina de História e até mesmo em Língua Portuguesa como simples exemplos e ilustrações, é um reducionismo de todo o potencial que podemos extrair deles, podendo, inclusive, condicionar a leitura por parte do aluno apenas com o objetivo de comprovar nos textos a gramática normativa que lhe está sendo exposta e, no caso da disciplina de História, apenas como uma mera ilustração dos conteúdos estudados.

Limita-se todo o desvaler de determinados textos. Os textos acabam por ter uma leitura, ou mesmo exploração, superficial. Tomemos como exemplo Auto da barca do inferno, de Gil Vicente, e todo o contexto que podemos extrair dessa leitura, questões referentes à usura, exploração do trabalho feminino, até mesmo a parte final, ao ser abordado o tema das Cruzadas e toda a ideologia que motivava a participação nas Cruzadas e a garantia da salvação para quem morresse em combate, ou mesmo o perdão dos pecados para quem aceitasse o chamado para participação nas Cruzadas, para não explorarmos outras questões possíveis.

Podemos mencionar também Morte e vida severina, de João Cabral de Melo Neto, com a questão dos movimentos migratórios, o latifúndio, a mecanização na lavoura, entre tantas outras questões mais que podem ser aborda- 
das, nesse último exemplo, ampliando ainda para disciplina de Geografia, bem como Sociologia, entre outras possibilidades mais.

Como várias vezes já nos referimos à literatura, cabe-nos a explicação de como utilizamos, neste trabalho, tal termo. Apesar de não ser fácil sintetizar a definição do que vem a ser literatura, Souza $(2007$, p. 46) propõe a seguinte:

[...] parte do conjunto da produção escrita e, eventualmente, certas modalidades de composições verbais de natureza oral (não escrita), dotadas de propriedades específicas, que basicamente se resumem numa elaboração especial da linguagem e na constituição de universos ficcionais ou imaginários.

Compreendendo o que tomamos como literatura, perguntamos:

- Qual é a razão da não utilização de textos literários como auxiliares, complementares aos conteúdos de História, em vez de simplesmente citações isoladas e descontextualizadas?

Justificamos que o esclarecimento desse ponto se faz necessário para evitar a compartimentalização dos conteúdos trabalhados com os alunos dos ensinos fundamental e médio no Brasil, já mencionada neste artigo, em que os alunos compreendem ou visualizam os conteúdos desconexos entre si, ficando a interdisciplinaridade apenas como um conceito e não como uma prática.

Assim, diante dessa crítica a um reducionismo de textos literários na disciplina de História, apresentarmos questões que nos levam à reflexão no intuito de ampliar o uso de textos literários, o que pode ocorrer também em outras disciplinas e não apenas em Língua Portuguesa/Literatura ou História.

Nossa crítica toma como objeto de análise principal o material de apoio disponibilizado pela Secretaria Estadual de Educação de São Paulo, nomeado como "Caderno do aluno", para o ensino médio, especificamente para a terceira série, na disciplina de História, material entregue a todos os alunos da rede pública de educação no estado, entre 2014 e 2017, na edição utilizada para análise.

Como uma análise mais pormenorizada dos materiais disponibilizados para todas as séries dos ensinos fundamental e médio ultrapassa os limites deste artigo, focamos nossa análise no material anteriormente citado, na situação de aprendizagem 1, titulada "Imperialismos, Gobineau e o Racismo". 
Compreendemos que outros materiais poderiam ser analisados, mas tomamos esse material em razão da quantidade de alunos que regularmente frequentam a rede pública do estado de São Paulo, sendo portanto um número bem expressivo e representativo.

\section{HISTÓRIA E LITERATURA: UM UNIVERSO A SER EXPLORADO}

Em cada um dos conteúdos - "situações de aprendizagem" - dos materiais disponibilizados para os alunos da rede pública estadual de educação do estado de São Paulo, encontramos textos de apoio, imagens, mapas, propostas de atividades por meio de questões dissertativas, objetivas, elaborações de resumos e sugestões de livros, assim como sugestões de filmes que podem ser analisados e, ainda, sites para acréscimo e aprofundamento dos conhecimentos abordados.

Ao analisarmos as sugestões para ampliação da compreensão do tema por parte do aluno, em especial os livros sugeridos, notamos a ausência de referências a textos literários que, em nossa compreensão, poderiam ser utilizados como parceiros no aprendizado e, concomitante, o estímulo à leitura desses textos, trazendo um acréscimo para a disciplina de História e para a fruição na leitura de textos literários.

Ao pensarmos na literatura como participante do ensino de História e não apenas coadjuvante nessa questão, ou total ausência em muitos casos, não estamos postulando que a leitura dos textos literários sugeridos por si só seja suficiente e que alcançará êxito no trabalho conjunto com os textos "não literários”, sem ter o devido preparo. A utilização da literatura também não descarta o emprego de outros materiais, entre eles os livros didáticos, o já mencionado "Caderno do aluno", além de outras fontes utilizadas pelo professor.

Ao trabalharmos com a literatura, é necessário que o conteúdo da disciplina de História, com o qual se pretende estabelecer uma ligação com o texto literário ou mesmo ampliar as leituras por meio deste último, já tenha sido abordado, exposto aos alunos, explorado por eles.

Exemplificamos esse ponto mencionando a leitura de "O navio negreiro", de Castro Alves, sem a correta contextualização da obra. A simples sugestão de leitura do poema não significa que o aluno passará a melhor compreender a realidade retratada no texto poético, a iniciar pelo próprio título da obra, que, sem o devido conhecimento histórico, pode não ser corretamente compreendido. 
Ao se apresentar o texto aos alunos, após a leitura dele, tendo o aluno o conhecimento das condições históricas a que o texto se refere, em específico o tráfico negreiro e as condições às quais eram submetidos muitos povos africanos na travessia do Atlântico, a leitura de "O navio negreiro" adquire outras cores, o texto proporcionará uma intensa reflexão sobre a crueldade praticada na época da escravidão, entre tantas outras possibilidades.

Não apenas em um texto literário, como um poema ou um livro, no todo ou em suas partes, mas também em outras obras artísticas, ocorre o mesmo fato, pois um observador, desprovido do conhecimento histórico da época em que uma pintura foi realizada, pode não compreender a expressão que o artista imprimiu na obra ou mesmo, por exemplo, a violência representada.

Ao vermos um quadro, como a tela Guernica, de Pablo Picasso, sem conhecermos a época em que o artista pintou o quadro ou mesmo a realidade que procura apresentar (a Guerra Civil Espanhola entre 1936 e 1939), ou ainda o quadro Massacre de São Bartolomeu, do artista François Dubois, sem ter o conhecimento do que foi o referido massacre, as circunstâncias nas quais ocorreu, ou mesmo sem conseguir perceber o conflito religioso retratado pelo artista, a interpretação do quadro ficará limitada ao que está explícito na obra, sem maior aprofundamento, em ambos os quadros.

Retornando à proposta deste artigo após essa breve excursão às artes plásticas, verifiquemos mais alguns exemplos dessas possibilidades de trabalho unindo a História com a Literatura por meio de dois textos literários, a saber, as obras A ilha misteriosa e A volta ao mundo em oitenta dias, ambas de Júlio Verne.

\section{LEITURA DOS IMPERIALISMOS NOS SÉCULOS XIX E XX POR MEIO DA OBRA A VOLTA AO MUNDO EM OITENTA DIAS}

Ao verificarmos o "Caderno do aluno" mencionado anteriormente, que apresenta o conteúdo relacionado ao imperialismo dos séculos XIX e XX, não encontramos a referência a um texto literário, como A volta ao mundo em oitenta dias ou $A$ ilha misteriosa. Ainda que tais obras não abordem diretamente a questão do imperialismo, podemos perceber na leitura delas questões referentes a esse período histórico.

Ao lermos A volta ao mundo em oitenta dias, em que o personagem que está mais em evidência na narrativa atravessa vários lugares/países com o 
intuito de provar a possibilidade do feito homônimo do título do livro, utilizando meios disponíveis para a época, ao atravessar a Índia, período em que o país era ocupado pela Inglaterra nos séculos XIX e XX, período conhecido como imperialismo. ${ }^{2}$ Encontramos no livro a seguinte referência:

Toda essa parte do alto Bundelkhand, pouco frequentada por viajantes, é habitada por uma população de fanáticos, persistente nas práticas mais terriveis da religião hindu. 0 domínio inglês não foi capaz de se estabelecer de maneira homogênea em um território submisso ao poder dos rajás e difícil de alcançar em seus inacessiveis redutos nos Vindhyas (VERNE, 2017b, p. 76).

O aluno, ao ler esse trecho, sem ter o conhecimento do momento histórico ao qual se refere a expressão “domínio inglês”, poderá ler o texto e compreender o domínio como um processo absolutamente natural, sem levar em consideração que esse domínio só ocorre em decorrência do processo de invasão e ocupação do território indiano por parte dos ingleses.

No discurso do autor do livro, a prática religiosa, que será realizada, é caracterizada como "práticas mais terríveis da religião hindu", em que o professor pode questionar essa interpretação, pois a invasão e ocupação do território indiano não é uma prática “das mais terríveis”, mas os rituais religiosos hinduístas, em parte, o são. Vale também destacar que a expressão religiosa é produto de "uma população de fanáticos", como se os cristãos nunca tivessem realizado, através do tempo, determinadas práticas que podem muito bem ser classificadas como fanáticas.

Ao nos determos na questão da ocupação do território indiano, podemos ampliar o debate com os alunos do ensino médio, realizando uma ligação com a disciplina de Geografia, possibilidade já mencionada anteriormente neste artigo, com destaque para o fato de que o livro como um todo é excelente para trabalhar a questão de "fusos horários", além de outros temas.

Acrescentamos a possibilidade do trabalho na disciplina de História das questões referentes à Revolução Industrial, a qual aparece no livro A volta ao mundo em oitenta dias, especialmente a força motriz gerada pelo vapor e a invenção mecânica desse período. Na obra, há ainda menção às locomotivas e

2 Encontramos várias formas diferentes de referência ao mesmo período histórico, tais como colonialismo nos séculos XIX e XX, neocolonialismo e imperialismo, sendo este último o termo utilizado por preferência neste artigo para nos referirmos à invasão e ocupação de partes dos continentes africano e asiático por países europeus; nos exemplos citados aqui, a invasão e ocupação da Índia pela Inglaterra. 
aos barcos utilizados para a travessia dentro dos países e pelos oceanos - novamente questões facilmente aplicadas à disciplina de Geografia.

Podemos notar outro trecho passível de ampliação do diálogo entre as disciplinas de História e Língua Portuguesa/Literatura, no qual encontramos as seguintes falas entre os personagens do livro:

Phileas Fogg tinha ouvido a palavra pronunciada por Sir Francis Cromarty e, tão logo a procissão desapareceu.

- 0 que é um sati? - perguntou.

- Um sati, Mr. Fogg - respondeu o brigadeiro-general -, é um sacrifício humano, mas um sacrifício voluntário. Aquela mulher que o senhor acabou de ver será queimada amanhã às primeiras horas do dia.

- Ah! Canalhas! - exclamou Passepartout, que não pôde conter o grito de indignação.

- E o cadáver? - perguntou Mr. Fogg.

- É o príncipe, seu marido - respondeu o guia -, um rajá independente do Bundelkhand.

- Como? - continuou Phileas Fogg, sem que sua voz traísse a mínima emoção.

- Esses costumes bárbaros persistem ainda na Índia? Os ingleses não conseguiram acabar com eles?

- Na maior parte da Índia - respondeu Sir Francis -, esses sacrifícios não são mais realizados, mas não temos nenhuma influência sobre estas regiões selvagens, e principalmente sobre este território do Bundelkhand. Todo o lado norte dos Vindhyas é palco de incessantes assassinatos e saques (VERNE, 2017b, p. 81).

Um mais efetivo diálogo entre as disciplinas com o aprofundamento da leitura da obra pode favorecer o acréscimo à leitura de trechos como os citados anteriormente, por meio da compreensão do aluno sobre as razões pelas quais o autor do texto refere-se a um lado como portador de práticas terríveis, e justamente um habitante do Reino Unido, Phileas Fogg, é quem idealizará o socorro para uma jovem que seria sacrificada; costume "bárbaro" que persistia justamente nas regiões que não foram totalmente dominadas pelo Reino Unido.

É possível perceber como a leitura de uma obra pode ser acrescida com as informações históricas que, por sua vez também, é enriquecida por meio da leitura da obra que faz referências a questões históricas abordadas. Cria-se com essas questões um processo cíclico ou, para utilizarmos um termo das ciências da natureza, de mutualidade, em que, em vez da atitude predadora, de apenas retirar do outro, existe o auxílio de um para com o outro ao mesmo tempo que é auxiliado. 
Propícia é também essa leitura de auxílio recíproco, mútuo, para trabalhar a competência específica 2 relativa às Ciências Humanas e Sociais, da Base Nacional Comum Curricular -BNCC (BRASIL, 2018, p. 573), como podemos ver a seguir:

\section{Competência Específica 2}

- Analisar a formação de territórios e fronteiras em diferentes tempos e espaços, mediante a compreensão das relações de poder que determinam as territorialidades e o papel geopolítico dos Estados-nações.

Encontramo-nos em um processo cíclico, em que uma questão auxilia na compreensão da outra, mas essas questões somente podem ser realizadas por meio de um trabalho conjunto, elaborado e planejado, e não por meio de atitudes isoladas, gerando, inclusive, confusão ou até mesmo questionamentos por parte dos alunos, como se o professor de uma determinada disciplina, no caso de História, estivesse interferindo na de Língua Portuguesa ou o contrário, o professor de Língua Portuguesa sendo questionado sobre o fato de as informações passadas para os alunos serem de competência do professor de História.

Com esse planejamento, os objetivos devem ser claros para os alunos, pois, do contrário, novamente será compreendida a literatura da forma que desejamos evitar: fornecedora de exemplos e/ou ilustrações para o conteúdo de História.

A proposta geral da BNCC (BRASIL, 2018, p. 562) para a área de Ciências Humanas Sociais prevê também que

[...] os estudantes desenvolvam a capacidade de estabelecer diálogos - entre indivíduos, grupos sociais e cidadãos de diversas nacionalidades, saberes e culturas distintas -, elemento essencial para a aceitação da alteridade e a adoção de uma conduta ética em sociedade.

O diálogo estabelecido em A volta ao mundo em oitenta dias é unilateral, pois partilha da visão de um colonizador sobre os costumes nomeados como "bárbaros" de outro povo, justamente o povo que está sendo explorado, que tem seu território invadido por uma potência imperialista na época da ambientação do livro.

Uma obra literária pode acrescentar à interpretação e ao julgamento de questões históricas diferentes perspectivas, que possibilitam aos alunos a tomada 
de posição diante de fatos, contudo, não ocorrerá esse acréscimo se os alunos não tiverem contato com o texto literário, se apenas tiverem acesso a fragmentos, a citações isoladas.

O despertar de uma atitude crítica por parte dos alunos pode ser ampliado com a utilização de um texto de literatura. Notamos que, por vezes, a literatura é acusada injustamente de ser amortizadora de uma leitura crítica, por ser ficcional, à diferença de textos históricos, verdadeiros em comparação com o mundo criado pela ficção.

Nas diretrizes da BNCC (BRASIL, 2018, p. 569), que podemos tomar como referência e indicação para a interação entre a Literatura e a História, apontamos para as discussões éticas em que

[...] os estudantes devem dialogar sobre noções básicas como o respeito, a convivência e o bem comum em situações concretas. A ética pressupõe a compreensão da importância dos direitos humanos e de se aderir a eles de forma ativa no cotidiano, a identificação do bem comum e o estímulo ao respeito e ao acolhimento às diferenças entre pessoas e povos, tendo em vista a promoção do convívio social e o respeito universal às pessoas, ao bem público e à coletividade.

Outra obra da literatura que mencionamos como exemplo a ser trabalhado conjuntamente com a disciplina de História é A ilha misteriosa, com destaque para o seguinte acontecimento que aparece no texto: a Guerra de Secessão nos Estados Unidos, também conhecida por Guerra Civil dos Estados Unidos.

Pensamos no diálogo entre a disciplina de História e essa obra no que concerne às questões sociais, econômicas e políticas que motivaram o conflito.

Esse conflito ocorreu entre 1861 e 1865, nos Estados Unidos, onde questões relacionadas à economia e à escravidão ocuparam o centro, onde os estados do Norte - ou "União" como eram conhecidos - batalharam contra os estados do Sul, a "Confederação", sendo a União contra a escravidão e os confederados a favor da manutenção do trabalho escravo. Essa fora uma das razões apontadas como principal para o conflito, uma vez que não era apenas uma questão ideológica, mas que afetaria duramente a economia sulista, que tinha por base a mão de obra escravagista.

Logo no início do livro A ilha misteriosa, Verne (2017a) nos coloca diante de prisioneiros que se juntam para escapar em um balão, sendo esses homens 
aprisionados após um malsucedido ataque a Richmond ${ }^{3}$ em fevereiro de 1865, último ano da referida guerra - o livro está ambientado nos últimos meses do conflito.

A ligação com a obra A volta ao mundo em oitenta dias é peculiar porque, enquanto nos continentes africano e asiático temos a ocupação por parte das potências europeias, muitas das quais escravagistas, temos na América do Norte um conflito "interno" de domínio e imposição de valores sobre o território, questão presente na obra $A$ ilha misteriosa.

Nos dois primeiros capítulos, encontramos mais diretamente referências à Guerra de Secessão, inclusive pela descrição e ocupação dos homens e do que estavam tentando realizar, a tomada de Richmond e assim o fim da referida guerra, e, ao conseguirem escapar utilizando um balão, circunstâncias adversas oriundas de uma tempestade conduzem o balão para mais de dez mil quilômetros de distância do país em que habitavam, no caso os Estados Unidos.

No decorrer da obra, algumas tecnologias existentes são recriadas na $A$ ilha misteriosa, como o telégrafo para facilitar a comunicação entre locais distantes na ilha, justamente um meio de comunicação tão utilizado durante a Guerra de Secessão, assim como o desejo dos colonos da criação de estradas de ferro para ligar diversas partes da ilha de forma rápida, tal como a expansão para o Oeste nos Estados Unidos, e assim como as estradas de ferro e o uso das locomotivas a vapor, que, com o telégrafo, eram um "símbolo" do progresso industrial dos países. Vale lembrar que, em A volta do mundo em oitenta dias, o telégrafo também aparece sendo utilizado.

Devemos ressaltar que as obras de Júlio Verne tomadas como exemplo são ambientadas em uma sociedade pós-Revolução Industrial e que muitos dos aparelhos e das máquinas que aparecem nos textos faziam parte do que, na época, era de maior representação tecnológica. Uma leitura que não realiza essa transposição para os alunos, em especial para uma geração acostumada às telas interativas de computadores/tablets/celulares, já fica fragmentada em suas possibilidades e interpretações. Um aluno, ao saber do funcionamento de um telégrafo, pode questionar se se trata de um meio antiquado e muito limitado ao comparar com os meios de que dispõe atualmente, mas deve-se transpor para a época em que o texto está ambientado.

Também temos, no decorrer da obra, a fala de personagens em alguns momentos a imaginar como encontrariam o país de origem quando conseguis-

3 Capital dos confederados na Guerra de Secessão. 
sem regressar, caso a Guerra de Secessão estivesse terminada, como estaria o país, unido ou não com o fim da guerra.

Tomando novamente questões norteadoras presentes na BNCC (BRASIL, 2018, p. 573), encontramos a seguinte diretriz:

\begin{abstract}
Competência Específica 1
- Analisar processos políticos, econômicos, sociais, ambientais e culturais nos âmbitos local, regional, nacional e mundial em diferentes tempos, a partir da pluralidade de procedimentos epistemológicos, científicos e tecnológicos, de modo a compreender e posicionar-se criticamente em relação a eles, considerando diferentes pontos de vista e tomando decisões baseadas em argumentos e fontes de natureza científica.
\end{abstract}

De acordo com a análise aqui realizada, a obra $A$ ilha misteriosa pode ser muito bem utilizada com esse objetivo, por abordar uma questão que faz referência às transformações políticas, econômicas, sociais (escravidão) e culturais: na ilha, como sabem que enfrentarão as mais diversas condições, os fugitivos desenvolvem, com base na tecnologia que conhecem e nos materiais de que dispõem, os aparatos para facilitar a sobrevivência e objetivar um possível retorno.

Em A ilha misteriosa, comparando com A volta ao mundo em oitenta dias, temos muitos outros elementos que podem ser trabalhados em outras disciplinas, como Química, Biologia, Geografia, Matemática, entre outras possibilidades mais.

Todo esse trabalho de aproximação entre as disciplinas e a leitura de um texto literário, ultrapassando a leitura como obrigatória ou mesmo apenas com objetivos de recreação, diversão, apenas para estimular o prazer pela leitura, questão que muitos livros procuram despertar, mas sem exceder ou ampliar os horizontes possíveis, é viável conforme temos apontado.

Todorov (2019, p. 93), ao defender a literatura, corrobora o que postulamos quando apresenta os seguintes questionamentos:

Que melhor introdução à compreensão das paixões e dos comportamentos humanos do que uma imersão na obra dos grandes escritores que se dedicam a essa tarefa há milênios? E, de imediato: que melhor preparação pode haver para todas as profissões baseadas nas relações humanas?

Na sequência, Todorov (2019, p. 93, grifo nosso) ainda cita exemplos de autores que em muito podem contribuir para os mais diferentes campos, ao apresentar mais os seguintes questionamentos: 
Ter como professores Shakespeare e Sófocles, Dostoievski e Proust não é tirar proveito de um ensino excepcional? E não se vê que mesmo um futuro médico, para exercer o seu ofício, teria mais a aprender com esses mesmos professores do que com os manuais preparatórios para concurso que hoje determinam o seu destino? Assim, os estudos literários encontrariam o seu lugar no coração das humanidades, ao lado da história dos eventos e das ideias, todas essas disciplinas fazendo progredir o pensamento e se alimentando tanto de obras quando de doutrinas, tanto de ações políticas quanto de mutações sociais, tanto da vida dos povos quando da de seus indivíduos.

Portanto, a utilização de textos da literatura não pode ser restrita a meros exemplos e ilustrações, ainda mais diante de tantas possibilidades, algumas das quais apresentamos neste artigo.

Não encontramos no "Caderno do aluno" que tomamos como referência para análise, para trabalhar a situação de aprendizagem que aborda o imperialismo nos séculos XIX e XX, nenhuma sugestão do uso de obras da literatura. Não caberia a sugestão de um texto que não demanda um grande empreendimento para sua compreensão como A volta ao mundo em oitenta dias ou ainda, ao abordar o que estava ocorrendo na mesma época na América do Norte, a Guerra de Secessão, não caberia a sugestão para o trabalho com $A$ ilha misteriosa? Acreditamos que deveriam existir tais indicações, além de outras possíveis, mas não as encontramos.

Não analisamos os demais materiais, mas tememos que, nas situações de aprendizagem em que temos o conteúdo da escravidão no Brasil colônia, tampouco encontraremos, quiçá, a menção ao poema "O navio negreiro", de Castro Alves, para não tomarmos muitos outros exemplos que podem ser utilizados.

\section{CONCLUSÃO}

Procuramos neste artigo demonstrar como as aulas de História no ensino médio ${ }^{4}$ podem ser acrescidas dos textos literários como ampliação do conheci-

4 Pontuamos apenas o ensino médio por compreendermos que os alunos nessa etapa do processo educativo já contemplam conhecimentos prévios necessários ou mesmo aprofundados para a compreensão de determinadas obras, à diferença do ensino fundamental em que determinados temas, como o imperialismo, são trabalhados nos anos finais ou mesmo no último ano, limitando o trabalho por parte do professor como idealizado neste artigo. 
mento por parte dos alunos e também termos um caminho que segue duas direções, a saber, não apenas a História contribuindo para os conhecimentos necessários para o aluno melhor compreender determinados textos literários, mas esses textos apresentando uma significativa contribuição para o conhecimento histórico, inclusive auxiliando os alunos na percepção de que existem diferentes interpretações sobre um mesmo acontecimento.

A disciplina de História e os conteúdos por ela apresentados, como protagonista da percepção de diferentes organizações sociais, de promotora da alteridade, da compreensão e do respeito, têm muito a ganhar com a inclusão efetiva da literatura em suas fileiras, muito além de uma mera citação por vezes descontextualizada de um texto literário.

Ao explorarmos as demais possibilidades contidas nos textos literários, ultrapassando os limites de tomá-los apenas como exemplos ou ilustrações dos conteúdos trabalhados, procuramos, por meio da utilização da literatura, realizar o que Sanches Neto (2013, p. 100) nos aponta: a literatura passaria a também funcionar como "uma passagem para o outro, para o outro que me permite ser múltiplo, e, portanto, mais humano”.

Também nos auxilia nesse entendimento Todorov (2019, p.76, grifo nosso) quando nos apresenta os textos literários como portadores da capacidade de

[...] nos estender a mão quando estamos profundamente deprimidos, nos tornar ainda mais próximos dos outros seres humanos que nos cercam, nos fazer compreender melhor o mundo e nos ajudar a viver. Não que ela seja, antes de tudo, uma técnica de cuidados para com a alma; porém, revelação do mundo, ela pode também, em seu percurso, nos transformar a cada um de nós a partir de dentro.

Cabe o destaque para o fato de a nossa "compreensão do mundo" não ser propiciada apenas e tão somente com a análise de informações históricas, mas talvez ser mais enfatizada por meio da literatura a nos revelar diferentes percepções, muito além daquelas a que estamos acostumados em textos históricos que se apresentam "imparciais" ou reveladores da "verdade".

Compreendemos as limitações para efetivar a proposta deste artigo, conforme aponta o documento Orientações educacionais complementares aos Parâmetros Curriculares Nacionais (PCN+) (BRASIL, 2006, p. 18), pois temos diante de tal tarefa 
[...] difíceis obstáculos que precisam ser transpostos. Primeiro, é preciso encontrar os pontos de contato reais entre as disciplinas da área. Em seguida, a partir desses pontos, é preciso estabelecer as pontes e o trânsito entre as disciplinas, que nem sempre interligarão da mesma forma todas essas disciplinas. Finalmente, é preciso identificar, analisar e desfazer falsas semelhanças, traduzir linguagens diferentes usadas para o mesmo objeto ou distinguir linguagens iguais usadas para identificar conceitos diferentes.

Outras obras dos autores mencionados ou mesmo de outros poderiam ser utilizadas, mas os limites deste artigo nos impõem a restrição das citações e dos exemplos que ora realizamos, assim como a ausência de exemplos de outros conteúdos abordados na disciplina de História, bem como diferentes épocas na História, atendo-nos apenas aos exemplos ocorridos nos séculos XIX e XX, ainda com maior ênfase no século XIX, período do imperialismo europeu e da Guerra de Secessão nos Estados Unidos.

As duas obras tomadas como referência neste artigo nos servem para apontar as possibilidades que são ampliadas por meio da utilização de outras obras literárias, do auxílio ou mesmo do caminhar em conjunto das disciplinas de História e Língua Portuguesa, mais especificamente na área de Literatura.

Apesar de as obras serem de ficção, elas nos mostram a possibilidade do trabalho conjunto, mas tal trabalho requer um planejamento bem realizado e adequado para que seja efetivo.

Não apresentamos a literatura como um recurso a solucionar as dificuldades encontradas pelos professores de História, tanto em relação à compreensão dos conteúdos como no que concerne à análise crítica destes, mas, sim, resguardados os devidos cuidados já destacados anteriormente, a utilização de obras literárias no ensino de História, por ser mais uma fonte, a acrescer, e muito sob nossa percepção, ao estudo, aprendizado e entendimento da História como um todo e não apenas como uma sucessão de fatos isolados.

Não estamos limitando o uso das questões que aqui foram propostas apenas para o ensino médio, mas, para uma utilização mais adequada aos alunos do ensino fundamental, necessitamos adaptar os textos literários e até mesmo outras abordagens que devem ser realizadas e que não foram devidamente contempladas neste artigo.

Cabe reforçar que nas obras citadas, como em outras a serem utilizadas, não estamos limitados apenas às disciplinas de Língua Portuguesa e História, pois outras disciplinas podem perfeitamente utilizar os livros aqui sugeridos, 
como as de Geografia, Biologia, Química, Matemática etc., questão que merece ser explorada e ampliada em artigos posteriores.

\section{Are these seas navigable? Literature as a participant and not just a coadjuvant in History teaching}

\section{Abstract}

This article seeks to discuss the use of literary texts as a support for teaching History, aiming to go beyond the view of literature only as a provider of examples. We understand this approach as a limitation. Thus, we propose the exploration of literary texts to improve the teaching methods of History and encourage students to read literature not only for Portuguese Language and Literature classes.

\section{Keywords}

Literature. History. Teaching.

\section{REFERÊNCIAS}

BRASIL. Orientações educacionais complementares aos Parâmetros Curriculares Nacionais (PCN+). Ciências Humanas e suas tecnologias. Brasília: MEC, 2006.

BRASIL. Base Nacional Comum Curricular (BNCC). Educação é a base. Brasília: MEC, Consed, Undime, 2018. Disponível em: http://basenacionalcomum.mec.gov.br/ images/BNCC_EI_EF_110518_versaofinal_site.pdf, acesso em 20/05/2019. Acesso em: 25 mar. 2021.

SANCHES NETO, M. O lugar da literatura: ensaios sobre inclusão literária. Londrina: Eduel, 2013.

SÃO PAULO (Estado). Material de apoio ao currículo do Estado de São Paulo: caderno do professor; História, ensino médio, $3^{a}$ série. São Paulo: Secretaria da Educação, 2014. v. 1.

SOUZA, R. A. Q. de. Teoria da literatura. São Paulo: Ática, 2007.

TODOROV, T. A literatura em perigo. Rio de Janeiro: Difel, 2019.

VERNE, J. A ilha misteriosa. Rio de Janeiro, Zahar, 2017a.

VERNE, J. A volta ao mundo em oitenta dias. Belo Horizonte, Autêntica, 2017b. 